\title{
The learning characteristics of primary care physicians
} KJME̊

Youngjon Kim

Department of Family Medicine, Wonkwang University Hospital, Iksan, Korea

\section{일차 진료의사의 학습 현상}

원광대학교병원 가정의학과

\section{김영전}

Purpose: This study analyzed the learning characteristics of primary care physicians that are necessary to develop proper educational support systems in continuing medical education.

Methods: The research participants were 15 physicians with an average of 8 years of experience in primary care clinics. The data were collected through in-person interviews with each participant and analyzed by keyword coding, expert review, and content elaboration.

Results: The learning styles of primary care physicians were classified as "reactive," "organized," and "exploratory," according to their problem-solving approaches in clinics. The types of learning interaction were "unilateral acquisition," "mutual exchange," and "organization participation." The primary motives of learning in clinics were the primary care physicians' recognition of accountability and the intrinsic enjoyment of learning itself.

Conclusion: For continuous professional development-i.e., the self-directed learning of primary care physicians with problemsolving approaches-learning interactions in professional communities should be considered in continuing educational support systems.

Key Words: Learning characteristics, Primary care physicians, Continuing medical education

\section{서론}

평생 의학교육(continuing medical education)의 측면에 서 의사의 학습연구는 좋은 의사 혹은 훌륭한 의사의 요건이 나[1,2] 질적 관리를 위한 연수교육에[3,4,5] 초점이 맞춰져 있는 것이 현실이다. 이러한 접근 방식은 현장경험을 통한 전 문성 계발 과정을 제대로 활용하지 못하는 문제가 있으며, 의
사를 일방적 교육이나 규제의 대상으로만 바라보게 되어 실 제적인 효과를 기대하기 어렵다는 비판을 받고 있다 $[6,7,8]$.

의사들의 학습은 주로 진료실에서 발생한 문제를 해결하는 과정에서 일어난다는 점에서 의과대학 학생들과 차이가 있으 며[8,9], 학습 목표와 방향을 스스로 결정하고 필요에 따라 적 절한 도구를 선택한다는 점에서 전공의 수련과도 구분된다. 한국에서 개원 의사나 봉직의의 경우 학습 과제와 학습 방식 은 병원이나 의원의 관리 및 경영과 밀접한 연관이 있으며, 폐
Received: June 8, 2015 • Revised: July 17, 2015 • Accepted: August 6, 2015 Corresponding Author: Youngjon Kim (http://orcid.org/0000-0002-0445-526X) Department of Family Medicine, Wonkwang University Hospital, 895 Muwang-ro, Iksan 570-974, Korea

Tel: +82.63.260.5183 Fax: +82.63.260.5180 email: firstsmile@hanmail.net
Korean J Med Educ 2015 Sep; 27(3): 213-219.

http://dx.doi.org/10.3946/kjme.2015.27.3.213

eISSN: 2005-7288

(C) The Korean Society of Medical Education. All rights reserved. This is an open-access article distributed under the terms of the Creative Commons Attribution Non-Commercial License (http:// creativecommons.org/licenses/by-nc/3.0/), which permits unrestricted non-commercial use, distribution, and reproduction in any medium, provided the original work is properly cited. 
쇄적인 의사 공동체 활동이 주요한 학습방편이 된다는 점에 서 일반 성인 학습자와도 차이가 있다.

평생 의학교육이 의사들의 계속적 전문성 계발(continuous professional development)에 기여하기 위해서는 무엇보다 도 의사들의 학습 특징과 맥락에 대한 이해가 선행되어야 한 다[8,9]. 진료 현장에서 의사들은 언제 학습의 필요를 느끼며, 어떠한 방식으로 학습하는지, 주요한 학습도구와 매체는 무 엇이며, 어떠한 학습지원을 기대하는지, 계속적 전문성 계발 을 위한 교육적 개입은 어떠한 방식으로 이루어져야 하며 이 를 실현하기 위한 교육환경의 설계는 어떻게 이루어져야 하 는지에 관한 보다 체계적인 논의가 필요하다.

따라서 본 연구는 의사들의 계속적 전문성 계발을 위한 기 초 연구로 한국에서 일차 의료기관에 근무하는 의사들의 실 제적인 학습현상을 탐색하고자 한다. 일차 진료기관의 방문 면담을 통해 의사들의 학습 현상을 분석하여 그 특징을 밝힘 으로써 평생 의학교육의 학습지원과 교육적 개입을 위한 토 대를 마련하는 것이 본 연구의 목적이다.

\section{대상 및 방법}

연구 대상은 서울지역 일차 의료기관에 근무하는 의사 15 명(남자 9 명, 여자 6명)이다. 연구 참여자의 전공은 가정의학 과 4 명, 내과 2 명, 마취통증의학과 2 명, 영상의학과 2 명, 이비 인후과 2 명, 정신건강의학과 1 명, 일반의 2 명이다. 연구 참여 자의 연령은 30 대 초반에서 40 대 후반에 분포하며, 일차 의료 기관 근무 경력은 평균 8년이다.

연구 방법은 선행 연구 고찰과 면담 준비, 면담 실시, 면담 분석의 순으로 진행되었다. 면담은 2014년 4월에서 5월 중에 연구자가 직접 참여자가 근무 중인 의원에 방문하여 일대일 대면으로 시행되었다. 동일 기관에 근무하는 각 2 인의 두 팀 은 집단면담(총 4인) 형태로 진행되었다. 면담 내용은 모두 녹 음 후 전사하였다. 면담 분석은 1 차 핵심용어 코딩, 2 차 전문 가 검토, 3 차 내용 정교화 순으로 진행하였다. 1 차 핵심용어 코딩은 주제분석의 방법론에 따라 전사된 면담의 내용을 코 드화하여 유사한 코드를 묶은 후에 이를 핵심용어로 범주화 하고 동일한 범주들을 포함하는 상위 주제를 도출하는 방식
이다. 2차 전문가 검토는 교육학 전문가(교육학 박사학위 소 지자/질적 연구 경험자) 2 인과 가정의학 전문의 1 인(총 3 인) 이 참여하여 내용분석의 적절성, 표현의 적절성을 검토하여 수정 및 보완 사항을 제시하였다. 내용 분석의 적절성은 핵심 용어 코딩 과정의 타당성을 평가하는 과정으로 분석 내용의 코드뮦음, 핵심범주, 주제(theme)의 도출과정을 각각 '적절, '부적절, '수정' 의견으로 나누어 제시하는 방식으로 이루어졌 다. 표현의 적절성은 핵심 범주 및 주제의 용어에 대한 적절성 을 '적절' 혹은 '부적절로 평가하여 '부적절'의 경우 하위 단계 를 수렴할 수 있는 상위 용어에 대한 추가적인 의견을 제시하 도록 하였다. 3 차 내용 정교화 과정은 1 차 핵심용어 코딩, 2 차 전문가 단계를 통해 수정된 핵심 범주 및 주제를 중심으로 연 구자가 면담의 전사 내용을 재분석하는 단계이다. 내용 정교 화 과정에서 연구자는 코딩을 통해 수렴된 내용을 다시 분화 의 과정을 통해 재분석하면서 내용 분석의 타당성을 재차 확 인하고 핵심범주 및 주제의 의미 및 관계를 정교화하였다.

\section{결과}

\section{1. 학습의 유형}

일차 진료의사의 학습은 주로 진료현장에서 발생한 문제나 환자의 요구를 해결하는 과정에서 이루어진다. 학습의 유형 은 대상자들이 직면하는 문제의 대처방식에 따라 '대응적 학 습, '체계적 학습, '탐색적 학습으로 구분되며 그 특징은 다음 과 같다(Table 1).

\section{1) 발생문제 대응적 학습}

대응적 학습은 진료 현장에서 발생한 문제를 실시간으로 해결하기 위해 수행되는 학습 형태를 말한다. 따라서 학습의 주된 내용은 당장의 문제를 해결할 수 있는 단순 지식정보나 간단 술기이다. 학습은 대부분 진료와 동시에 혹은 환자와 환 자 진료 사이에 이루어지며, 의사들은 주로 학회의 가이드북, 동료 의사(의료진), 교과서 및 매뉴얼, 웹 자료 등 활용하여 정보를 습득한다.

사실 1차 진료 위주로 가는데요. (중략) 뮈가 발진이 났어요. 
Table 1. The Learning Types of Primary Care Physicians

\begin{tabular}{|c|c|c|c|}
\hline & \multicolumn{3}{|c|}{ Type of learning } \\
\hline & Reactive learning & Organized learning & Exploratory learning \\
\hline Purpose of learning & To solve patients' complaints & $\begin{array}{l}\text { To understanding of the problems } \\
\text { in depth }\end{array}$ & $\begin{array}{l}\text { To explore and understand the new } \\
\text { issues }\end{array}$ \\
\hline Learning features & Immediate, responsive & Systematic, theoretical & Exploratory, proactive \\
\hline Learning range & $\begin{array}{l}\text { Limited (information to solve the } \\
\text { patients' complaints) }\end{array}$ & $\begin{array}{l}\text { Extended (knowledge and skills } \\
\text { related to the problems) }\end{array}$ & Knowledge in new areas \\
\hline Learning contents & Tips and simple information & General theory and background & New information and techniques \\
\hline
\end{tabular}

발진 환자가 왔는데 잘 모르는 것이 있잖아요. (중략) 보호자 랑 같이 책을 찾아보는 경우도 있었고요. (중략) 보호자 밖에 잠깐 계시라고 그런 다음에, 찾아봐서 다시 불러서 설명을 하 는 경우가 많았어요.

소아 환자를 보는 경우 (중략) 육아까지 알아야 할 것 같은 거예요. 엄마들이 저한테 육아에 대해서 물어보고 그러는데, 학교에서 배운 게 없지만 그래도 여기저기 인터넷 찾아봐가 지고 알려드리고 (후략).

개원 의사는 (모든 전공 영역에 걸쳐) 다 봐요. 내 전공 환자 만 오는 것도 아니고 (중략) 모른다고 보내면 다시 안 오니까 급하면 얼른 알만한 친구들한테 전화하고, 환자 내보내고 매 뉴얼 찾아보고 (후략).

학습의 내용은 의학지식과 술기를 포함해 환자관리, 병원 경영 및 회계, 의료법규 등 다양한 영역을 포함한다. 면담에 참여한 대부분의 의사들은 다양한 문제에 대응하기 위해 수 시로 정보를 습득하고 있다고 밝혔으나 일부 응답자들은 개 원 초기를 제외하고는 진료 현장에서 새로이 지식정보나 기 술을 습득하게 되는 경우가 거의 없었다고 밝혔다.

\section{2) 문제 해결을 위한 체계적 학습}

체계적 학습의 유형은 진료 현장에서 발생한 문제가 시발 점이 되어 관련 내용이나 이론을 보다 정밀하게 학습하는 형 태를 말한다. 이러한 학습 유형은 대응적 학습에 비해 비교적 오랜 시간과 노력이 소요되며, 고차원적 인지활동과 연습을 필요로 한다. 연구에 참여한 의사들 중 일부는 진료 중 여유 시간 혹은 진료 이후 따로 시간을 내어 학술서적이나 연구논
문을 탐독하거나 학회나 연구모임 혹은 세미나 등을 통해 지 식정보를 습득하고 술기를 훈련한다고 밝혔다.

단골 환자들이랑은 랏뽀(환자-의사관계)가 생기는데 (중략) 딴 곳에 보내기 애매할 때가 있잖아요. 한 번은 계속 설사하 는 환자가 왔는데 굳이 다른 데 안가고 나한테만 자꾸 찾아와 서 그 환자 때문에 (따로 시간을 내어) 설사 진단하고 치료하 는 약제를 다 훓어보기도 하고.

어떤 한 분야에서 좀 고수의 경지에 올랐다라고 평가 받는 분 들이 보통 소그룹으로 5 명 내지 10 명 정도, 1 박 2 일 정도 일 정 잡아서 세미나를 진행하거든요. 통증 치료 하면서 그런 곳 에 신청을 해서 집중적으로 배우고.

체계적 학습을 하는 요인에 대해 응답자들은 "환자에게 문 제에 대해 좀 더 자세히 설명해 줄 필요를 느껴서", "결과가 마음에 들지 않아", “더 효과적인 방법의 필요", “부작용이나 환자의 불만 발생” 등의 진료의 질적 향상을 언급하였다. 부수 적인 의견으로 “동료 의사가 학문적 근거나 원리에 대해서 물 어봐서" 문헌을 찾아보고 “프로그램이나 학회에서 발표"하기 위해 문헌 연구를 했다는 응답이 있었다.

\section{3) 문제 대비를 위한 탐색적 학습}

문제 대비를 위한 탐색적 학습 유형은 의사 자신이 새로운 학습 과제를 설정하여 관련 지식정보나 술기를 탐구하는 형 태를 말한다. 새로운 약물이나 치료 방법에 대한 업데이트, 새 로운 진료 영역의 개발을 위한 정보습득, 보편화 되지 않은 특 정 술기나 치료 방식의 탐구가 여기에 속한다. 면담에 응한 일 차 진료의사들은 주로 국내외 연구논문이나 제약회사 영업사 
원을 통해 새로운 의료 정보를 습득하고 있다고 밝혔다.

요새 들어 방송이 많아지니까 환자들이 (건강보조식품) 중에 뭐가 좋은지 자꾸 물어봐요. 처음에는 별 것 없다고 생각해서 (중략) (환자가) 좋다고 하니까 왜 그런지 궁금해서 찾기도 하고 또 취급도 해야 해서 (관련 문헌들) 다 찾아보고, 제약회 사 연락해서 (주요 건강보조식품에 대한) 설명도 듣고 그러면 서 (약물 처방의) 판단의 기준이 생겼어요.

그게 이런 저런 문제를 겪어보면 나름의 해결 방식이 생겨요. 잘하는 병원이 있거든 (중략) 저는 (미용영역 진료를 결정하면 서) 아예 선배 병원에 가서 한 달 동안 스파르타 교육을 받았어 요 환자 관리하는 것이랑, 시술방법이랑, 청구하는 문제랑.

면담에 응한 일부 의사들은 특정 치료나 진단 분야에서 “고 수”라고 알려진 유명한 의사 혹은 친밀도가 있는 “잘되는” 의 원이나 병원을 찾아 특정한 지식이나 기술을 습득한 적이 있 다고 응답하였다. 학습의 내용은 새로이 소개되는 치료 방식 이나 술기 혹은 병원관리, 환자 교육 등 다양한 분야이다. 교 육비용은 무료로 진행되는 경우도 있으나 대부분은 특별 경 비를 지불한다고 밝혔다.

\section{2. 학습의 형태}

학습의 형태는 일차 진료의사들이 누구와 어떻게 무엇을 가지고 학습하는지를 의미한다. 일차 진료기관에 근무하는 의사들의 학습 형태는 다른 학습자 및 학습 자료의 상호작용 방식에 따라 일방적 습득, 양방의 상호교류, 조직 내 참여의 형태로 나타난다.

\section{1) 일방적 습득}

일방적 습득방식은 특정한 교수자 혹은 이미 만들어진 학 습 자료 즉, 서적이나 연구논문, 웹 자료 등을 이용하여 필요 한 의료지식이나 기술을 빠르게 습득하는 방식을 의미한다. 특정 기술을 익히기 위해 동료 의료인을 찾아가거나 진료에 필요한 정보를 얻기 위해 병원 내 자료, 우편물, 웹 사이트를 이용하는 것이 여기에 속한다. 일방적 습득방식은 비교적 짧 은 시간 내에 필요한 정보를 얻을 수 있는 장점이 있어 일차 진료의사들이 가장 많이 활용하는 학습 형태이다.
병원으로 학회지 오는 거 최신 지견이나 가이드라인 보고 (중 략) 검색하면 (진료 관련 자료가) 다 있어서요. 요통환자 운동 법 같은 것 요새 $\bigcirc \bigcirc$ (동영상 사이트)에 나오는 거 보고 해 보고 배워서 환자들에게 가르쳐 주기도 해요.

저는 동료 선생님한테 물어보거나 또는 통상 저희 대학동기 들 중에서 남아있는 서브 스페셜 친구들한테 직접 물어보거 나 아니면 또 제가 연락하고 있는 교수님들께 전화나 만남을 통해 여쭈어 봅니다.

\section{2) 양방의 상호교류}

양방의 상호교류의 학습은 다양한 방식을 통해 학습 자료 나 또 다른 학습자인 의료인들과 교류하면서 지식과 기술을 습득하는 형태이다. 상호교류의 방식은 오프라인에서 면대면 면담, 통신수단을 이용한 정보교류, 웹 사이트 등에서의 다자 간 방식으로 나타난다. 양방의 상호교류 방식에서 의사들이 학습자인 동시에 다른 의료인에게 필요한 정보를 제공하고 새로운 학습자료를 만들어내는 정보 제공자의 역할을 수행하 기도 한다.

저희 의국 출신들 단체 $\bigcirc 00$ 방(SNS 의 일종) 있거든요. 모 르거나 애매하면 수시로 $\bigcirc 0 \bigcirc$ 에게 가서 의견을 물어봐요. 혼자 판단하는 것보다 둘이 생각하는 것이 좋고 (중략) 의견 물어보면서 서로 알려주고 (중략) 문자로 "이렇게 했는데 이 렇게 하는 거 맞나요?” 이렇게 물어보고, 제가 경험이 있으면 알려 주고.

000 (의사 대상의 사이트)에 진료 틈틈이 들어가요. 가끔 (의료문제에 대한) 논쟁이 있거나 DRG (포괄수가제) 같은 것 나오면 이런저런 논쟁이 생기는데 이런 데는 글도 달고 다 른 사람이 올려놓은 글에 답글도 읽어요. 청구문제나 보험정 보 같은 것도 올라오고 (아는 내용이면) 답도 하고.

\section{3) 조직 내 참여 방식}

조직 내 참여 방식은 공인된 기관이나 조직에 통해 필요한 학습 내용을 습득하는 방식을 말한다. 국내외 학회의 강의나 세미나에 참여하거나 대학 및 대학원의 진학하여 학습하는 
형태가 가장 일반적이다. 면담에 응한 일차 진료의사들은 "대 학원에서 스포츠 의학"을 전공하거나 "미국의사면허" 시험공 부를 했으며, "노인의학 자격증 연수강좌" 등에 참여하고 있다 고 응답하였다. 이러한 학습방식은 특정 기술이나 자격을 획 득하기 위해 여러 학회 소모임, 연구회 등을 활용하는 것으로, 상당한 비용과 시간이 소요되는 단점이 있으나 학습의 결과 로 공인된 자격을 획득하거나 특정 의료 기술을 빠르게 습득 할 수 있는 장점이 있다.

연수강좌와 큰 규모의 학회를 다녀요. 현재 일과 관련된 거 위주로 (연수강좌를) 들어요. (중략) 작년 같은 경우는 초음 파와 복부 초음파학회를 가서 초음파 배웠고요. 작년부터 노 인의학 자격증 따려고 연수강좌 때때로 듣고 있어요.

\section{3. 학습의 동인}

학습의 동인은 의사들이 학습을 하게 되는 원동력을 의미 한다. 일차 진료의사들의 1 차적 학습 동인은 의사의 책무 인 식이며, 2차적 동인은 학습을 통한 자기계발이다.

\section{1) 의사의 책무 인식}

학습 동인으로서 의사의 책무 인식은 '환자 건강과 만족'을 자신의 역할과 의무로 받아들이는 것이다. 면담에 응한 일차 진료의사들은 의과대학 교육이나 수련만으로는 역동적인 의 료현장에서의 환자의 다양한 진료요구(needs)를 충족하기에 부족하다고 지적하며 '계속적인 학습이 필요하다고 응답하였 다. 응답자 중 일부는 의사의 직무에 대해 "모르는 게 죄가 되 는 직업”, “의학은 재미보다는 의무”라고 평가하거나 의사로서 자신에 대해 "진료에 대해 모르거나 실수한다는 것을 받아들 이기 힘들고", "(내 잘못으로) 컴플레인 받으면 하루가 다 우 울”하다고 토로하였다.

환자들 중에 약 이름 하나하나 검색해서 다 알아보고 오는 사 람이 있어요. 의사가 말한 것 듣고 의사 떠보기도 하고 (평가 하기도 하고) 왜 이 약 썼냐, 어디에 쓰는 약이냐 물어 보는데 (중략) 의사가 의사 대우를 받으려면 일단 알아야 $\cdots$.

(내시경 시술을) 안 하면 모를까 하려면 제대로 해야겠다 싶 어서 여기저기 쫓아다녀서 배우고 연습하고 (중략) 내가 몰라
서 환자 놓치면 그건 (의사의 도리가) 아닌 것 같아서 $\cdots$.

이러한 학습이 불가피한 이유로는 "의학이 정체되어 있는 분야가 아니라 계속 개발되는 분야"라는 과학으로서의 의학 의 학문적 특성과 “방송이나 인터넷에 널려있는 정보”라고 표 현되는 의료 정보의 대중화, "말 한마디 잘못하면 인터넷에 공 개되고 매장되는" 의료 소비자의 권리에 대한 민감도의 증가 가 있다.

\section{2) 개인의 가치지향}

학습의 동인으로서 개인의 가치지향은 학습 자체 혹은 학 습을 통해 얻어지는 다른 이득 때문에 학습에 참여하게 되는 요소를 말한다. 면담에 응한 일부 의사들은 진료실에서 책을 보게 되는 이유를 “학습하지 않는 상태가 지속되면 불안”하다 거나 “똑같은 일이 무료해져서”라고 표현하기도 하였으며, 특 정 술기의 역량을 계발하면서 "나만 아는 것이 생기는 즐거움" 혹은 “어렴풋이 알았던 것을 다시 리뷰하면 자극이 되는” 만 족감이 있다고 평가하였다. 봉직기간 동안 외국 의사면허 시 험을 준비해서 자격을 취득한 한 응답자는 "아무것도 안 하는 것이 싫어서" 학습을 하게 되었다고 응답하였고, 대학원에서 스포츠 의학을 수학하고 있다는 또 다른 응답자는 "박사에 대 한 동경”을 대학원 진학의 결정 요소로 꼽았다.

의사 공동체 참여도 주요 요소로 언급되었는데, 정기적으 로 자신의 전공 학술대회에 참석하고 있다는 한 응답자는 "학 술대회에서는 900 전문의 1000 과 의사라는 소속감'을 확 인할 수 있어 참석하게 된다고 응답하였고, 또 다른 응답자는 정기 학술대회 장소에서 의국모임이 매해 열리고 있다고 언 급하면서 “동료 의사와의 만남”을 중요한 이유로 언급하였다. 동일 의국 출신의 응답자 두 명은 의국의 공식적인 학술행사 에 소속감이나 관계 때문에 참여한다고 밝혔다.

병의원의 경영이나 경제적 이득을 학습의 동인으로 보는지 에 대해서는 응답자 간의 답변이 엇갈렸다. 대부분의 응답자 는 경제적 이득이 자신의 학습과 관련이 있다고 하였으나 '경 제적 이득이 학습 여부와 학습 내용을 결정하지는 않는다고 답하였다. 응답자들은 의사들의 자기계발이나 노력이 장기적 으로는 병원의 경영에 좋은 영향을 줄 것이라고 답하면서도, 현재 시점에서는 "개원의사가 공부해서 돈을 더 벌겠다는 건 말이 안 되고", “의사가 돈을 벌려면 진료시간을 늘이던가, 영 
업을 해야지, 공부를 하면 그 병원 망한다"고 응답하며 오히려 학습이 병원 경영이나 경제적인 문제의 걸림돌이 된다고 답 하였다. 반면 “돈을 벌기 위해” 특정 술기를 배우기 시작했다 고 밝힌 한 의사는 "수익에 도움이 되지 않는다면 (의료)기술 을 안 배웠다’고 응답하면서 실력을 향상을 위한 노력은 ‘돈' 혹은 '경제적 반대급부라고 언급하였다.

\section{고찰}

연구 결과에 의하면 일차 진료의사들은 현장에서 발생한 문제나 환자의 요구를 해결하는 과정에서 학습한다. 학습 내 용은 진료에 필요한 단순 정보나 술기, 의학적 이론, 비전공 진료 영역의 개발까지 다양하게 나타났다. 의사들의 학습 형 태는 의사의 성향이나 여건에 따라 일방적 정보습득, 상호교 류를 통한 공유, 공동체 참여 등으로 나타나며, 학습의 주요동 인은 의사로서의 자신의 역할 인식과 책무의식이다.

Bennett et al. [8]은 미국 의사들의 계속적인 전문성 계발 을 위한 평생 의학교육의 비전을 밝히면서 문제바탕학습을 모형화하고 있는 의사들의 자기 주도적 학습체제에 보다 관 심을 가질 것을 강조한 바 있다. 본 연구 결과에 의하면 의사 들의 학습 유형은 학습의 목적과 방식에 따라 반응적 학습, 체 계적 학습, 탐구적 학습의 유형으로 구분될 수 있다.

진료현장에서 의사들이 마주하는 문제들은 학습의 주요 기 회이자 방법이다. 의사들은 문제를 해결하는 과정을 통해 자 신만의 특정한 학습 방식을 만들어가는데[9], 이러한 형태는 지속적이며 일상적인 형태를 지닌다. 그러나 어떤 학습자는 보다 체계적이며, 탐구적인 학습의 유형을 보이는가 하면, 어 떤 경우에는 대응적인 해결책을 강구하는 수준에서 학습이 머무는 경우가 있다.

Bereiter \& Scardamalia [10]은 전문가 학습의 특징이 진 화적 문제 해결(progressive problem solving) 방식에 있다 고 밝힌 바 있다. 진화적 문제 해결은 문제를 해결하는 과정을 통해 아직 발생하지 않았지만 발생할 가능성이 있는 잠재적 인 문제들의 해결 역량까지를 습득하는 것이다. 문제의 원인 을 분석하고 해결에 필요한 요소를 파악하여 관련된 지식과 기술을 학습함으로써 경험에 근거한 비공식적인 지식이 기존
지식과의 연결되어 전문가적 역량을 갖추게 된다는 것이다. 계속적 전문성 계발의 측면에서 볼 때, 대응적 학습의 형태는 경험의 습득이라는 측면에서 의미는 있으나 문제 해결 역량 을 강화하는 데 제한적인 한계가 있다.

평생 의학교육의 제공과 관련하여 관심을 갖는 부분은 '어 떤 의사들이 어떻게 학습을 자각하며, 언제 어떠한 도구나 매 체를 통해 학습하는지'에 관한 정보이다. 본 연구 결과에 의하 면 학습을 자각하게 하는 주요한 요소는 의사 자신의 역할과 직무 범위에 관한 책무 인식이다. 의사들은 의료 현장에서 직 면한 문제가 '내가 해결해야 할 문제인지를 스스로 결정하고 $[8,9]$, 이 결정에 따라 학습의 방법과 유형도 스스로 선택한 다. 환자가 제기하는 문제가 쉽고 단순한 경우와 내가 해결할 문제가 아니라고 판단한 경우에 의사들은 학습의 의지를 보 이지 않으며, 그 외의 경우에는 문제의 유형과 성격 및 난이도 에 따라 다른 학습 방법을 사용한다. 의사들은 계속적인 자기 계발을 의사의 의무로 인식하고 있었고, 자신의 학습에 있어 전문가로서 정체성을 중요하게 고려한다고 밝혔다. 이러한 결과는 의학교육의 주요한 역량으로 언급되고 있는 의사의 자기정체성, 의학의 책무의식이 평생 의학교육에 중요한 요 소임을 다시 한 번 확인하게 한다.

일차 진료의사들의 학습의 형태와 관련해서 주목할 부분은 의사들의 상호교류 방식이다. 의사들은 오프라인과 일부 인 터넷 공간에서 공식적 혹은 비공식적으로 다른 사람의 경험 을 공유하고 자신의 의견을 피력하며 학습하고 있다. 온라인 과 오프라인 상에서의 상호교류 방식은 대개 자율적인 활동 이며, '정보를 얻고, 모델링을 하며, 피드백을 받는' 등의 다양 한 학습 형태를 보인다. 의사들의 이러한 학습 형태는 현재는 비록 제한된 시공간에서 일부 의사들에게 보이나 전문가 집 단의 정보와 경험의 교류라는 측면에서 새로운 학습 형태의 가능성을 시사한다.

의사들의 학습 현상에 대한 이해는 계속적인 전문성 계발 을 위한 평생 의학교육의 변화를 위해 몇 가지 측면에서 시사 하는 바가 있다. 첫째, 의사들이 일상적으로 수행하고 있는 문 제기반, 진료기반 방식의 학습지원과 교육의 개입이다. 만들 어진 강의에 학습자를 초대하는 방식이 아닌 이미 학습하고 있는 많은 의사들이 어떻게 보다 더 효과적으로 문제해결역 량을 양성할 수 있을지 지원체계를 고민할 필요가 있다[7]. 둘 
째는, 의사의 자기정체성과 책무의식에 대한 교육의 강화이 다. 계속적 자기계발은 좋은 의사의 덕목이며[1,2], 의학교육 의 주요한 교육성과이다. 기본 의학교육 및 졸업 후 교육의 연 속선상 속에서 전문직업성의 교육은 평생 의학교육의 성과와 긴밀하게 연계되어 있다. 셋째는 의사 커뮤니티를 활용한 학 습 기회의 개발과 제공이다. 현재 온라인 상에서는 기관주도 나 상업적 목적의 의사 전용의 커뮤니티가 여러 개 있다. 그러 나 이러한 커뮤니티는 의사들의 참여가 거의 없거나 구직이 나 구인의 용도로만 사용되는 한계가 있다. 자율적인 참여가 가능하면서도 다양한 의학적 지식과 경험이 공유될 수 있는 커뮤니티가 ‘학습의 장이 될 수 있을지 가능성과 의미를 고민 해 볼 필요가 있다.

Acknowledgements: None.

Funding: None.

Conflicts of interest: None.

\section{REFERENCES}

1. Baik SH. The way of making a good doctor. Korean J Med Educ 2010; 22: 249-256.

2. Lee YM, Ahn DS. A preliminary study for exploring the attributes of being a "good doctor". Korean J Med Educ 2007; 19: 313-323.
3. Kim KS. For better continuing medical education. J Korean Med Assoc 2004; 47: 184-186.

4. Kim S, Shin YS, Kim JH. Executive strategies for CPD program development and enhancement. J Korean Med Assoc 2008; 51: 577-585.

5. Research Institute for Healthcare Policy. A study for providing an accreditation standards for continuing professional development program in Korea. Seoul, Korea: Research Institute for Healthcare Policy; 2013.

6. Yoo SY. Survey of CME recognition and satisfaction among primary care physicians. Korean J Med Educ 2006; 18: 87-95.

7. Ministry of Health and Welfare. A study on continuing education status of health professionals. Seoul, Korea: Ministry of Health and Welfare; 2013.

8. Bennett NL, Davis DA, Easterling WE Jr, Friedmann P, Green JS, Koeppen BM, Mazmanian PE, Waxman HS. Continuing medical education: a new vision of the professional development of physicians. Acad Med 2000; 75: $1167-1172$.

9. Slotnick HB. How doctors learn: physicians' self-directed learning episodes. Acad Med 1999; 74: 1106-1117.

10. Bereiter C, Scardamalia M. Surpassing ourselves: an inquiry into the nature and implications of expertise. Chicago, USA: Open Court; 1993. 